\title{
A metodologia Dicumba como uma tempestade de possibilidades para o desenvolvimento do ensino de Química
}

\author{
Everton Bedin ${ }^{*}$, José Claudio Del Pino**
}

\section{Resumo}

Este artigo apresenta resultados de uma atividade investigativa realizada por meio do aprender pela pesquisa à luz da metodologia de ensino denominada Dicumba, proporcionando ao aluno a conexão de sua vivência com os saberes do conteúdo da ciência química e ao professor a percepção da necessidade de uma formação continuada para aperfeiçoar seu saber intradisciplinar. A pesquisa se enquadra em um viés qualitativo-quantitativo e foi desenvolvida, durante três meses, com uma turma de segundo ano do ensino médio. A coleta de dados foi realizada por meio da observação participante e da aplicação de um questionário estruturado. Os dados coletados foram interpretados à luz da análise de conteúdos de Bardin e apresentados por meio de quadros e gráficos. Ao término, conclui-se que a metodologia Dicumba é fiel quanto ao desenvolvimento de atividades pedagógicas que levam os alunos à apren- dizagem, pois estes colocam-na como algo inovador, sendo uma ação de aprimorar e ressignificar saberes de forma universal-bilateral. Por fim, sugere-se que o aprender pela pesquisa seja, urgentemente, incorporado nas práticas pedagógicas, buscando a formação do sujeito e a estruturação curricular a partir do contexto e da vivência do aluno, para, então, construir conhecimentos científicos relacionados à ciência química.

Palavras-chave: Aprendizagem centrada no aluno. Aprender pela pesquisa. Metodologia Dicumba.

\section{Primeiras ideias}

A tentativa de melhorar e qualificar o ensino de química na educação básica tem sido um dos grandes desafios con-

Doutor e pós-doutorando em Educação em Ciências Química da Vida e Saúde na Universidade Federal do Rio Grande do Sul (UFRGS). Professor adjunto do curso de Química da Universidade Luterana do Brasil (Ulbra). E-mail: bedin.everton@gmail.com

** Doutor em Engenharia de Biomassa pela Universidade Federal do Rio Grande do Sul (UFRGS) e pós-doutorado na Universidade de Aveiro, Portugal. Professor associado da UFRGS e professor orientador dos Programas de Pós-Graduação em Educação em Ciência Química da Vida e Saúde e em Química, ambos na mesma instituição. E-mail: delpinojc@yahoo.com.br 
temporâneos de professores e pesquisadores da área, uma vez que associar o contexto, o interesse e o desejo sobre o que aprender dos diferentes alunos às ideias e aos conceitos científicos do componente curricular de química, em um viés democrático e qualitativo da vivência do aluno, é uma tarefa complexa e, ao mesmo tempo, não singular.

Todavia, inúmeras propostas de ensino surgem como alternativas para melhorar este quadro que assombra não apenas as práticas pedagógicas e a qualificação do ensino, mas também a busca e a permanência dos jovens nas escolas. Nesse sentido, torna-se importante destacar que não são apenas as metodologias de ensino, a didática do professor e as diferentes formas de abordar os conteúdos que impactam na qualificação do ensino, mas também outros inúmeros fatores, como o empenho e a motivação do aluno, a infraestrutura da escola, a gestão democrática, os desafios e a problemática da dicotomia entre ensino e pesquisa na formação docente durante o curso de graduação.

Neste texto, destacam-se as questões de ensino relacionadas à pesquisa, à prática e à teoria, porque se entende, a partir das colocações de Mello (2000 apud MÜLLER, 2007), que é extremamente importante que o professor vivencie essas ações durante o processo de formação no curso de licenciatura, a fim de que possa, posteriormente, munido de competências e habilidades, relacioná-las durante sua práxis. Entretanto, a autora enfatiza que esta vivência, na grande maioria dos cursos de formação de professores, infelizmente, ainda não se encontra de forma significativa e relevante no processo de formação crítica.

Acredita-se que este processo de formação docente seja extremamente necessário, já que se considera que o ensino na educação básica, em grande parte, ainda permanece de forma instrucionista e tecnicista; o repasse de informações, conceitos e conteúdos por parte do professor, sem nenhuma ação discente e reflexão consciente do meio, ainda é predominante. Esse ensino desqualifica a proposta democrática e pedagógica de ensino de qualidade, pois o aluno, ao não participar do próprio processo de formação, não consegue lograr satisfação de aprender a aprender, intervir de forma crítica e reflexiva na realidade, construir argumentos e ideias próprios e fundamentados cientificamente, desenvolver a capacidade problematizadora, o pensamento autônomo e o espírito científico-investigativo.

Nesse cenário, Bedin destaca que

[...] somente a utilização de processos, o emprego de técnicas e mudanças nas ações didáticas não são suportes o suficiente para fazer o estudante compreender e aplicar conceitos e métodos em seu dia a dia (2015, p. 41).

Assim, o autor afirma ser necessário "instigar o educando a pensar, analisar 
e fazer, por meio de seus conhecimentos, mudanças dinâmicas no mundo atual" (2015, p. 41), a fim de que possa entender e compreender suas ações por meio da construção e reconstrução de saberes cooperativos e participativos. Basso, Nevado e Fagundes ajuízam ser fundamental compreender que o processo de aprender é resultado da

[...] interação operacional dos sujeitos que constroem o conhecimento enquanto agem, interagem e se comunicam com o seu meio, com outros indivíduos e com objetos do conhecimento científico, tecnológico, social e artístico, dos quais eles desejem e necessitem se apropriar (2003, p. 44).

Nesse sentido, buscando um ensino voltado para a formação autônoma e significativa do aluno, colocando-o como protagonista na própria formação de conceitos e saberes que se vinculam à sua realidade, à sua curiosidade e ao seu desejo de aprender, neste artigo, objetiva-se apresentar resultados de uma atividade investigativa desenvolvida por meio do aprender pela pesquisa à luz da metodologia de ensino Desenvolvimento Cognitivo Universal-Bilateral da Aprendizagem (Dicumba), ${ }^{1}$ proporcionando ao aluno a conexão de sua vivência aos saberes do conteúdo de química e ao professor a percepção da necessidade de uma formação continuada para aperfeiçoar seus saberes docentes e o pleno conhecimento intradisciplinar.
Este artigo, além de apresentar um nova proposta de ensino, culminando com as ações de ensinar e aprender cooperativamente, e mostrar diferentes possibilidades de trabalhar o contexto do aluno nos conteúdos científicos da disciplina de química, justifica-se pela ação do aprender pela pesquisa, possibilitando aos diferentes professores (de educação básica e superior, pública e privada) a comunhão de ideias e saberes relacionados à importância da pesquisa atrelada à ensinagem, apontando a necessidade de repensar e readaptar o espaço educativo e o currículo de química à luz da pesquisa não arbitrária e unidimensional em sala de aula.

\section{Aportes teóricos}

Na educação básica, são perceptíveis um comportamento e um posicionamento de passividade da grande maioria dos alunos; essa percepção pode ser derivada de duas vertentes: 1 - o modelo de aula ainda é baseado na transmissão de informações que podem, a partir da autonomia e da criticidade do professor, ser desnecessárias para a construção cognitiva do aluno; 2 - os alunos não se sentem instigados e estimulados à aprendizagem, uma vez que esta ocorre de forma mecânica e sem vínculo contextual; logo, buscam apenas concluir suas tarefas em tempo necessário e passar em 
provas e exames, que, muitas vezes, não exigem mínimas habilidades cognitivas.

Nesse sentido, é importante pensar na formação desses sujeitos enquanto pessoas críticas e autônomas, uma vez que fazem parte da sociedade, e a educação básica é o princípio da sua formação formal e acadêmica. Assim, é preciso pensar em metodologias de ensino a serem desenvolvidas e aplicadas na educação básica - destaca-se a importância de fortalecer esse viés, também, na formação inicial de professores - para que os alunos se sintam instigados a pensar e, a partir da prática de formação individual e coletiva, desenvolver competências e habilidades necessárias para que se tornem cidadãos aptos a enfrentar e modificar o contexto em que estão inseridos.

Este pensamento se faz urgente na contemporaneidade porque o professor, como responsável por uma área do saber, e a escola, enquanto instituição de ensino, são agentes mobilizadores de conhecimentos para a qualificação da aprendizagem, por meio de um planejamento criterioso e do uso de diferentes metodologias de ensino (LIBÂNEO, 2013). O planejamento, como ponto crucial na constituição dos objetivos docentes, deve servir para que o professor possa pensar e estruturar fragmentos de ensino que consigam fazer com que o aluno, motivado e entusiasmado pelo ato de aprender, perceba seu contexto no mundo científico, utilizando os saberes adquiridos ou construídos para explicar fenômenos naturais e/ou artificiais. Libâneo (2013) define a sala de aula como um espaço de inter-relações entre professor, aluno e conhecimento.

Dessa forma, o estudo a partir da pesquisa centrada no aluno em sala de aula é uma das melhores formas de fazer o sujeito começar a aprender a partir da própria ação, para que o professor assuma o papel de mediador/facilitador do processo de aprendizagem, e não mais de um mero transmissor de informações, de modo que o ambiente de ensino passe a ser percebido de forma dinâmica e dialógica. Nesse sentido, Galiazzi (2014) expõe que a pesquisa em sala de aula é uma possibilidade de superar o ensino tradicional, baseado em cópias e reproduções.

Com a prática da pesquisa em sala de aula, de forma ativa e crítica, a partir da orientação e do direcionamento do professor, os alunos são capazes de construir argumentos, hipóteses e respostas a perguntas que emergem de uma problematização, constituindo e reconstituindo saberes à medida que a pesquisa avança in loco (DEMO, 2015; GALIAZZI, 2014). Autores como Demo (2015) e Galiazzi (2014), além de recomendarem a pesquisa como essência cotidiana na formação e nas atitudes do professor em sala de aula, defendem o educar pela pesquisa, apresentando-a como uma proposta teórica e metodológica de ensino, alicerçando-se no desenvolvimento de 
habilidades, na constituição do sujeito como um ser autônomo e responsável pelos seus conhecimentos.

Todavia, apresenta-se e defende-se a proposta da metodologia Dicumba, derivando-se no aprender pela pesquisa, realizado a partir do interesse do aluno - a escolha pelo problema de pesquisa a ser resolvido parte daquilo que o aluno deseja e, então, é direcionado e aprimorado para o conteúdo específico da disciplina. Portanto, entende-se que Dicumba (desenvolvimento cognitivo universal-bilateral da aprendizagem) procede da ideia da formação acadêmica e sociocultural do sujeito enquanto cientista, daquele que tem, ou despertará, veemência e curiosidade pelas ciências.

Nessa perspectiva, a metodologia Dicumba, apesar de estar entrelaçada à ideia de pesquisa em sala de aula para qualificar e instigar a formação contínua do professor da educação básica, liga-se diretamente à aprendizagem do aluno a partir daquilo que ele gosta ou tem afinidade, extrapolando a ideia dicotomizada entre ensino e aprendizagem, proporcionando meios para que o estudante seja o construtor de seu aprendizado e de sua história, vinculando-o cognitivamente à sua capacidade crítica e reflexiva. Portanto, por meio desta pesquisa não arbitrária e unidimensional, o estudante, muitas vezes, poderá aprender com os próprios erros, aprender a aprender, fazer e se refazer e, de forma legítima, am- pliar seu acervo cognitivo à medida que lê e busca respostas para o desconhecido.

É necessário pensar que o aprender pela pesquisa, assim como o educar pela pesquisa, traz algumas dificuldades explícitas, pois, se os alunos, assim como os professores, não forem inseridos e constituídos ativamente neste processo, que exige diferentes habilidades e competências para mobilizar saberes em um repertório diferenciado de conhecimentos, podem ocorrer reações controvérsias, uma vez que a pesquisa exige, além do domínio do conhecimento e de saberes para filtrar as informações necessárias, paciência e aptidão para diagnosticar aquilo que é necessário dentro do passageiro. Algumas dessas reações, nem sempre conscientes, são identificadas por Galiazzi, Moraes e Ramos (2003) como mecanismos de resistência, que se manifestam pela inércia na elaboração das atividades.

Nesse viés, no momento de realizar a pesquisa a fim de aprender cientificamente por meio de algo de seu interesse, entende-se que o educando seja capaz de não apresentar resistências quanto a: 1 necessidade de ser ativo e ter iniciativa na busca pelas respostas das questões; 2 - paciência necessária para pesquisar e filtrar informações necessariamente coerentes àquilo que deseja; 3 -importante ação de ler, interpretar e compreender a escrita dos outros e, a partir dessas ações, elaborar eticamente o próprio texto de pesquisa; 4 - necessidade de 
escrever e relacionar o conteúdo científico ao seu contexto, buscando maximizar o meio a partir daquilo que pesquisa, afinal, o vezo de escrever é algo que se aprimora com o passar do tempo e em relação à capacidade de exercitá-lo; 5 capacidade de apresentar rigorosamente a conexão existente entre a disciplina ou o conteúdo científico e a pesquisa realizada, proliferando novas ideias e saberes, seja por meio da argumentação crítica ou da escrita problematizada, a partir do saber científico presente em seu contexto.

Basicamente, a proposta de aprender pela pesquisa pode ser compreendida a partir de um pentagrama (símbolo da união e da síntese), no qual é possível perceber as cinco principais ações que se entrelaçam na medida em que a metodologia Dicumba é desenvolvida (Figura 1).

Figura 1 - Pentagrama: ações desenvolvidas na metodologia Dicumba

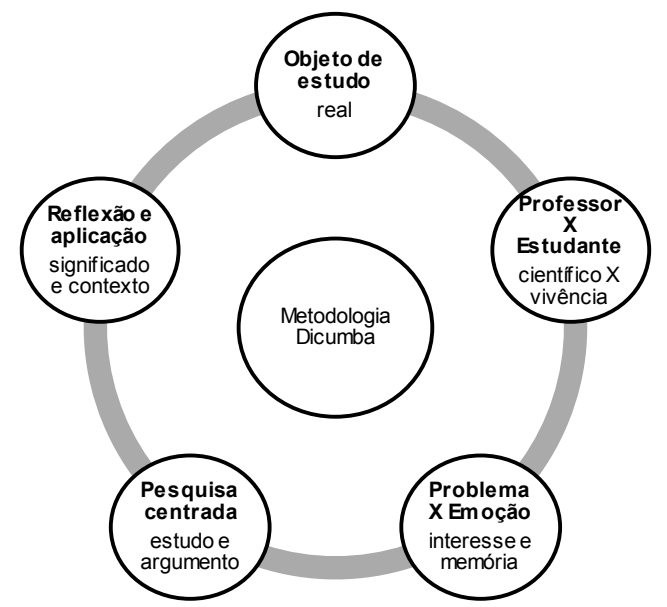

Fonte: elaboração dos autores.
Com o pentagrama, conclui-se que esse tipo de pesquisa pressupõe a relação entre os sujeitos envolvidos no processo de ensinagem de forma assídua, participativa e cooperativa, contemplando um objeto de estudo real, que deriva da curiosidade do aluno a partir de sua realidade. Além disso, por ser uma pesquisa centrada nos objetivos do aluno, os quais derivam particularmente de seus desejos e se relacionam com sua vivência, desenvolve-se a partir da problematização do interesse do aluno e de suas emoções à luz da memorização, em meio a estudos e reflexões que levam à argumentação sobre o objeto estudado e ressignificado em seu contexto.

Portanto, entende-se que aprender pela pesquisa, apesar de ser algo extremamente imponente para/na educação básica, uma vez que deriva daquilo que o educando deseja aprender, tornando-o, a partir desta ação, autor relevante em sua formação, é algo que requer competências e habilidades além dos atos de pesquisar, planejar e sintetizar, firmando um acordo com uma renovação na forma de construir e reconstruir conhecimentos, afinal, como assegura Demo (2015, p. 9), “[...] a pesquisa busca na prática a renovação da teoria e na teoria a renovação da prática, a educação encontra no conhecimento a alavanca crucial da intervenção inovadora".

De outra forma, a metodologia Dicumba proporciona ao aluno construir e 
reconstruir, a partir da problematização e do questionamento, ideias e hipóteses para, dentro de suas especificidades e singularidades de pesquisa, encontrar (re)soluções para a pesquisa que se realiza a partir do desejo e da vontade de estudar. Isso é suficiente para mostrar que o aluno, em primeira instância, multiplica seus saberes em relação ao tema em que deseja se aprofundar e, a partir da pesquisa direcionada pelo professor, começa a realizar novas investigações e a problematizar aquilo que busca à luz dos saberes científicos. Essa ação não se torna cansativa e maçante para o aluno, pois está diretamente relacionada a um tema que ele mesmo escolheu para pesquisar. Então, a aprendizagem ocorre a partir da movimentação de conhecimentos pré-existentes em seu cognitivo.

Assim, o ciclo de pesquisar e repesquisar os saberes científicos faz com que o aluno desenvolva competências de argumentar e questionar cada vez mais criticamente, uma vez que se complementa em novos saberes que se inter-relacionam a partir de uma temática exclusiva. As ações de pesquisar, criar hipóteses, repesquisar, argumentar e questionar cada vez mais criticamente à luz dos saberes científicos fazem com que o aluno busque o desenvolvimento cognitivo de forma universal e bilateral da aprendizagem, pois é exatamente isto que se possibilita ao pôr em movimento a Dicumba em sala de aula: "o questionar se aplica a tudo que constitui o ser, quer sejam conhecimentos, atitudes, valores, comportamentos e modos de agir" (MORAES; GALIAZZI; RAMOS, 2004, p. 12).

A seguir, a síntese apresentada na Figura 2 demonstra a ação da argumentação crítica a partir de problemas e hipóteses no processo de pesquisar.

Figura 2 - Representação da ação do aprender pela pesquisa

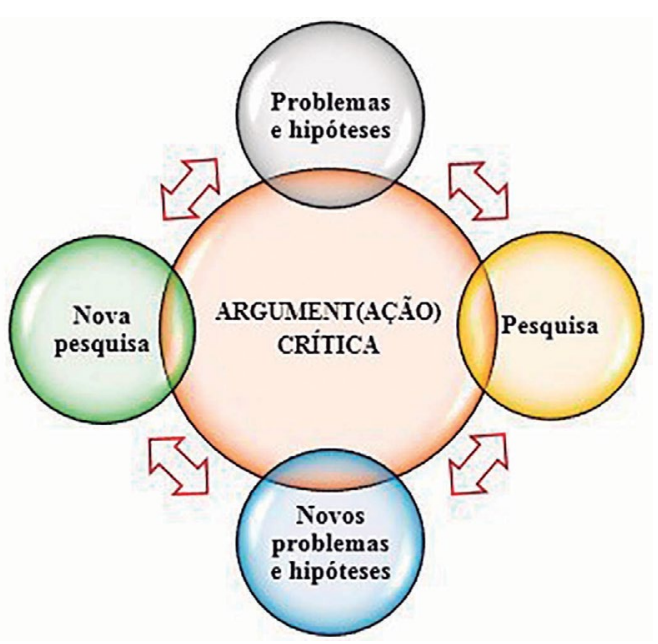

Fonte: elaboração dos autores.

Na Figura 2, é perceptível que qualquer passo do aprender pela pesquisa leva o aluno a uma argumentação crítica - uma ação sobre a própria ação do aprender -, fecundando-se em novos saberes e conhecimentos a partir da pesquisa e da criação de hipóteses e problemas que possam, com o auxílio do professor - visto como um orientador do processo de aprendizagem -, instigar o aluno a aprender cientificamente, des- 
pertando seu caráter ativo no desenvolvimento de ações significativas em relação à sua formação.

Trata-se, portanto, de relacionar o conteúdo ao conhecimento pré-existente do aluno; o inverso não ocorre. A proposta de aprender pela pesquisa é que o professor consiga auxiliar o aluno a construir conhecimentos científicos na sua vivência - é uma relação de saberes do macro para o micro -, não é uma ação de contextualizar, apesar de isso ser extremamente importante no ensino de química. Afinal, é a partir da pesquisa, que está diretamente relacionada a algo do contexto do aluno, que este busca os conhecimentos científicos, elencando significados aos fenômenos naturais e artificiais que fazem parte do seu dia a dia. Logo, como em um processo dialético, o aprender pela pesquisa desencadeia-se em novos problemas e hipóteses, fazendo com que o aluno continue a pesquisar, mas de forma mais ampla e criteriosa, para responder os novos problemas que surgem.

Assim, conclui-se que o aprender pela pesquisa é uma nova forma de o professor, na sala de aula, extrapolar os muros da escola e estimular o estudante a aprender os saberes da ciência química a partir daquilo que lhe é útil e agradável. Ademais, ainda se acredita que a metodologia Dicumba é suficientemente significativa para demonstrar ao aluno a imperatividade de uma aprendizagem contínua, necessitando de aperfeiçoamento e apro- fundamento de forma crítico-reflexiva, para que se possa usar os múltiplos saberes para modificar, positivamente, $o$ seu contexto sociocultural.

\section{Desenho da pesquisa}

Os resultados desta pesquisa foram desenhados a partir da intervenção na realidade do aluno pela ação concreta do professor titular da disciplina de química, uma vez que por meio da proposta do Aprender pela Pesquisa pode-se extrair ideias e concepções dos alunos em relação aos processos de ensino e aprendizagem, buscando vincular o contexto do aluno a partir de seu desejo de estudar aos saberes científicos da disciplina.

Assim, com uma pesquisa que concebe o aluno como autor de sua formação a partir da curiosidade e do interesse pelo saber, a fim de provocar mudanças e transformações significativas no ensino, buscou-se o desenvolvimento da atividade com a participação de 15 alunos de uma turma de segundo ano do ensino médio, sendo 11 meninas e 4 meninos, de uma escola pública de São Leopoldo, município adjacente à Porto Alegre, capital do estado gaúcho.

O desenvolvimento da metodologia de ensino Dicumba, a qual proporciona ao aluno o aprender pela pesquisa, dando-se ênfase ao seu contexto para ressignificá-lo por meio dos saberes científicos da disciplina de química, 
ocorreu em oito etapas: 1 - explicação da metodologia aos estudantes por parte do professor; 2 - escolha de tema a ser pesquisado individualmente pelo aluno; 3 - socialização dos temas e formação de grupos a partir de assuntos iguais, não semelhantes, para o desenvolvimento da pesquisa de forma colaborativa e cooperativa; 4 - pesquisa centrada no interesse do aluno; 5 - socialização da pesquisa em sala de aula de forma oral; 6 - direcionamento da pesquisa pelo professor à luz do conhecimento químico; 7 - pesquisa centrada na conexão entre o tema selecionado pelo aluno e os conceitos químicos direcionados pelo professor; 8 - socialização da nova pesquisa realizada para a turma.

Assim, com um conhecimento mais elaborado e que, de certa forma, enraíza-se nos conhecimentos químicos gerais acerca de um tema investigado, os alunos desenvolveram competências relacionadas a argumentação crítica, autonomia de escolhas e, principalmente, capacidade da ação-reflexão-ação, uma vez que, por meio da conjugação do esforço intelectual com o compromisso problematizador da pesquisa, foram trabalhados saberes sociais, culturais e científicos.

\section{A pesquisa}

A pesquisa enquadra-se em um viés qualitativo-quantitativo, uma vez que busca, entre os fios condutores, verificar como os alunos validam a ideia da inserção da metodologia de ensino Dicumba em sala de aula e entender o que eles consideram significativo para ser estudado nas aulas de química a partir do aprender pela pesquisa, com ênfase nas justificativas teóricas; logo, tem-se como finalidade primordial a "demonstração lógica das relações entre conceitos e fenômenos, com o objetivo de explicar a dinâmica dessas relações em termos intersubjetivos" (MENDES, 2006, p. 11).

Nessa perspectiva, para a coleta dos dados, utilizou-se, além da observação durante a prática desenvolvida em três meses, a aplicação de um questionário ao término de todo o desenvolvimento da atividade. A utilização do questionário advém da ideia de qualificar e intensificar os dados obtidos, uma vez que, por meio da coleta exploratória, permite-se suscitar riqueza e flexibilidade à pesquisa, "fornecendo os dados básicos para o desenvolvimento e a compreensão das relações entre os atores sociais e sua situação" (GASKELL, 2002, p. 65).

Do mesmo modo, partindo-se de uma pesquisa desenvolvida pelo aluno a partir de algo de seu contexto, pois é ele quem escolhe o que quer estudar e investigar, de acordo com Patton (1980) e Glazier e Powell (2011), os dados advindos de uma pesquisa qualitativa são definições particularizadas de fenômenos, comportamentos, referências diretas de sujeitos sobre suas experiências e informações 
com rigor em detalhes e profundidade de interações entre os sujeitos. Portanto, para a análise e a interpretação desses dados que derivam da observação atuante do professor e do questionário, enquanto técnica de investigação com $o$ objetivo de entender "opiniões, crenças, sentimentos, interesses, expectativas, situações vivenciadas, etc." (GIL, 1999, p. 128), dos sujeitos, utilizou-se a análise de conteúdos de Bardin, que é:

Um conjunto de técnicas de análise das comunicações visando a obter, por procedimentos sistemáticos e objetivos de descrição do conteúdo das mensagens, indicadores (quantitativos ou não) que permitam a inferência de conhecimentos relativos às condições de produção/recepção destas mensagens (BARDIN, 2011, p. 47).

De outra forma, Bardin (2009) coloca a análise de conteúdos, enquanto método científico de análise de dados advindos de pesquisas qualitativas, como um conjunto de ações que busca analisar as comunicações por meio de procedimentos sistemáticos e objetivos de descrição do conteúdo das mensagens.

Assim, destaca-se que, para a aplicabilidade correta do método, a partir de conjecturas de interpretação das mensagens e dos enunciados, a análise de conteúdo carece de uma organização, conforme Bardin (2009), em torno de três fases. A pré-análise, destacada como a primeira fase, é organizada em procedimentos definidos e maleáveis, envolvendo uma leitura superficial das escrituras que serão submetidas à análise. A segunda fase é determinada pela exploração do material; neste momento, criam-se, a partir da análise e da classificação das escrituras, as unidades de compilação com técnicas de decodificação, classificação e categorização. A última etapa é demarcada pelo tratamento dos resultados, parte importantíssima do trabalho que faz emergir, por meio dos dados interpretados, categorias e justificativas que extrapolam o conteúdo manifestado no questionário, pois o pesquisador precisa torná-los significativos a ponto de entender o conteúdo concentrado, o sentido implícito de pesquisar algo que se encontrava imediatamente apreendido.

\section{Resultados e discussões}

Para o desenvolvimento da pesquisa, na sala de aula do segundo ano do ensino médio, houve a formação de dez grupos de trabalhos, sendo dois trios, uma dupla e sete individuais. No Quadro 1, apresenta-se a primeira questão do questionário disponibilizado pelo professor no fim dos três meses de trabalho, sendo possível perceber o tema e a justificativa que os alunos escolheram para desenvolver a pesquisa. 
Quadro 1 - Temas e justificativas apresentadas pelos alunos na metodologia Dicumba

\begin{tabular}{|l|l|l|}
\hline \multicolumn{2}{|l|}{ Trabalhos } & \multicolumn{1}{c|}{ Justificativas de escolha } \\
\hline T1 & Produção de cola & $\begin{array}{l}\text { "É um tema que eu sinto interesse e acredito ser fácil, além de apre- } \\
\text { sentar muita química." }\end{array}$ \\
\hline T2 & Perfume & $\begin{array}{l}\text { "Escolhi por ser interessante e gostar muito de perfumes. Quero } \\
\text { saber sobre a exalação e a fabricação destes, até caseiro se tiver." }\end{array}$ \\
\hline T3 & Cigarro eletrônico & $\begin{array}{l}\text { "Entender o quanto o cigarro é ruim e não o usar, pois o tabaco pode } \\
\text { levar à morte e é muito utilizado, até aqui na escola." }\end{array}$ \\
\hline T4 & Leucemia & $\begin{array}{l}\text { "Por ser um tema pouco falado e ser uma doença que, instantanea- } \\
\text { mente, leva a pessoa à morte senão tratado corretamente, é impor- } \\
\text { tante saber." }\end{array}$ \\
\hline T5 & Usina nuclear & $\begin{array}{l}\text { "Acho o tema interessante e quero saber como pode acontecer } \\
\text { acidentes em usinas nucleares." }\end{array}$ \\
\hline T6 & Maquiagem & $\begin{array}{l}\text { "É um tema que me atrai por eu usar muito; quero saber quais os } \\
\text { efeitos em meu corpo." }\end{array}$ \\
\hline T7 & Cervejas & $\begin{array}{l}\text { "Eu bebo cerveja e não sei como elas são fabricadas. Quero saber } \\
\text { isso por ser algo que me desperta curiosidade." }\end{array}$ \\
\hline T8 & Jogos eletrônicos & $\begin{array}{l}\text { "Eu jogo muito. Tenho interesse em saber mais sobre, pois estou } \\
\text { diariamente em contato com diferentes tipos de jogos." }\end{array}$ \\
\hline T9 & Smartphone & $\begin{array}{l}\text { "Por ser algo muito utilizado na vida das pessoas; ele está ocupando } \\
\text { o lugar social." }\end{array}$ \\
\hline T10 & Música & $\begin{array}{l}\text { "Escolhi a música porque ela está diariamente em minha vida, es- } \\
\text { tou envolvida por ela o tempo todo. Ela me relaxa e me enche de } \\
\text { energia." }\end{array}$ \\
\hline
\end{tabular}

Fonte: elaboração do autor.

Ao analisar essas informações, pode-se perceber que os alunos escolheram temas que estão, diretamente, relacionados a algo que lhes atrai intensamente, seja pelo interesse ou pela curiosidade, como pode ser interpretado nas justificativas de T1, T5 e T7, por exemplo. Além disso, há justificativas que relacionam o tema com algo íntimo, como T2, T6 e T10, e que relacionam o tema com algo social, como T3, T4 e T8. Assim é a metodologia Dicumba, o aluno escolhe o tema para aprender o conteúdo cientificamente, indiferente de ter ou não ligação direta com a disciplina química, pois este é o trabalho do professor: direcionar o interesse do aluno aos saberes científicos.

Apesar de as justificativas estarem coerentes com a proposta Dicumba, em T1 é possível averiguar uma colocação que merece destaque e reflexão, além de um posicionamento crítico do professor, pois o grupo justifica a escolha pelo fato de o tema ser fácil e ter relação com 
a química. A proposta Dicumba não elimina temas que possuem vínculo primordial com o conteúdo que está sendo trabalhado pelo professor em sala de aula, pois não se trata de uma proposta de pesquisa arbitrária e linear ao currículo dos conteúdos mínimos, mas uma pesquisa em que o aluno, ao fazer-se autor da aprendizagem a partir daquilo que lhe é interessante, consiga conectar seu contexto aos saberes científicos, com a orientação do professor; logo, o tema a ser selecionado para a pesquisa não precisa ter relação direta com a química, pois, neste desenho, entram as competências e as habilidades do professor.

Todavia, isso não significa que a proposta Dicumba instiga o aluno a pesquisar algo que não está diretamente relacionado à química, o que se propõe é uma pesquisa de interesse, a fim de que $o$ professor, na sequência da apresentação do tema, possa direcionar a pesquisa aos conteúdos da química. Esse desenho é importante porque, de acordo com Boruchovitch e Bzuneck (2004), o professor que leva seus alunos a refletirem além do conteúdo da sala de aula e promove a aprendizagem. Logo, a proposta Dicumba pressupõe que a aprendizagem em química pode partir de qualquer ponto; basta que o aluno escolha o que deseja aprender e que o professor, munido de competências, habilidades e saberes plenos, faça relações com a química.
Assim, o professor estimula o aluno a pensar em um tema que, em meio ao próprio interesse, possa gerar um problema real ou fictício; a resolução deste problema por meio da pesquisa faz com que o aluno entre no ciclo da elaboração de hipóteses e argumentações, fazendo o exercício da ação-reflexão, para aprimorar seu entendimento autônomo e crítico. Contudo, para que esse processo se concretize, é fundamental que o professor desenvolva um planejamento com vistas ao processo qualitativo da ensinagem, buscando que o aluno se torne um ser crítico, ativo e pensante, construindo significados e relações entre o seu contexto e o científico.

Portanto, trabalhar com a metodologia Dicumba exige que o professor apresente muito mais que conhecimentos intradisciplinares, mas que esteja ciente da necessidade de um planejamento, pois este, na visão de Anastasiou, Cavallet e Pimenta (2003), é o alicerce que permite ao professor a organização do conteúdo/ conhecimento de forma sistematizada; logo, permite-se ao estudante realizar as conexões pessoais do seu mundo com o conteúdo científico de química. Afinal, "a inteligência constitui o estado de equilíbrio para o qual tendem todas as adaptações sucessivas de ordem sensório-motora e cognitiva, bem como todas as permutas assimiladoras e acomodadoras entre o organismo e o meio" (PIAGET, 1988, p. 32). 
Outra questão apresentada no questionário estimulava o aluno a pensar sobre os benefícios da pesquisa em sua formação sociocultural. Em especial, nesta questão, o professor disponibilizou algumas asserções e solicitou que os alu- nos as numerassem de 1 a 10 , considerando o número 10 a de maior prioridade e o número 1 a de menor prioridade. As asserções disponibilizadas pelo professor estão no Quadro 2.

Quadro 2 - Asserções disponibilizadas no questionário sobre a pesquisa na formação do aluno

\begin{tabular}{|l|l|}
\hline A. Conhecimento químico & F. Interesse pelo saber científico \\
B. Conhecimento sobre o assunto & G. Criticidade \\
C. Aprender a pesquisar & H. Autonomia de escolhas \\
D. Interesse e curiosidade & I. Saberes gerais sobre a química \\
E. Mobilização de competências & J. Aprender a aprender \\
\hline
\end{tabular}
Fonte: elaboração do autor.

A partir das respostas dos estudantes, realizou-se o Gráfico 1, que mostra, além das asserções sobre os impactos da pesquisa na formação sociocultural do aluno, os apontamentos dos estudantes por trabalho realizado sobre todas as asserções; logo, têm-se as asserções de A a J e os trabalhos de T1 a T10.

Gráfico 1 - Resultado das colocações dos grupos de trabalhos sobre as asserções do questionário

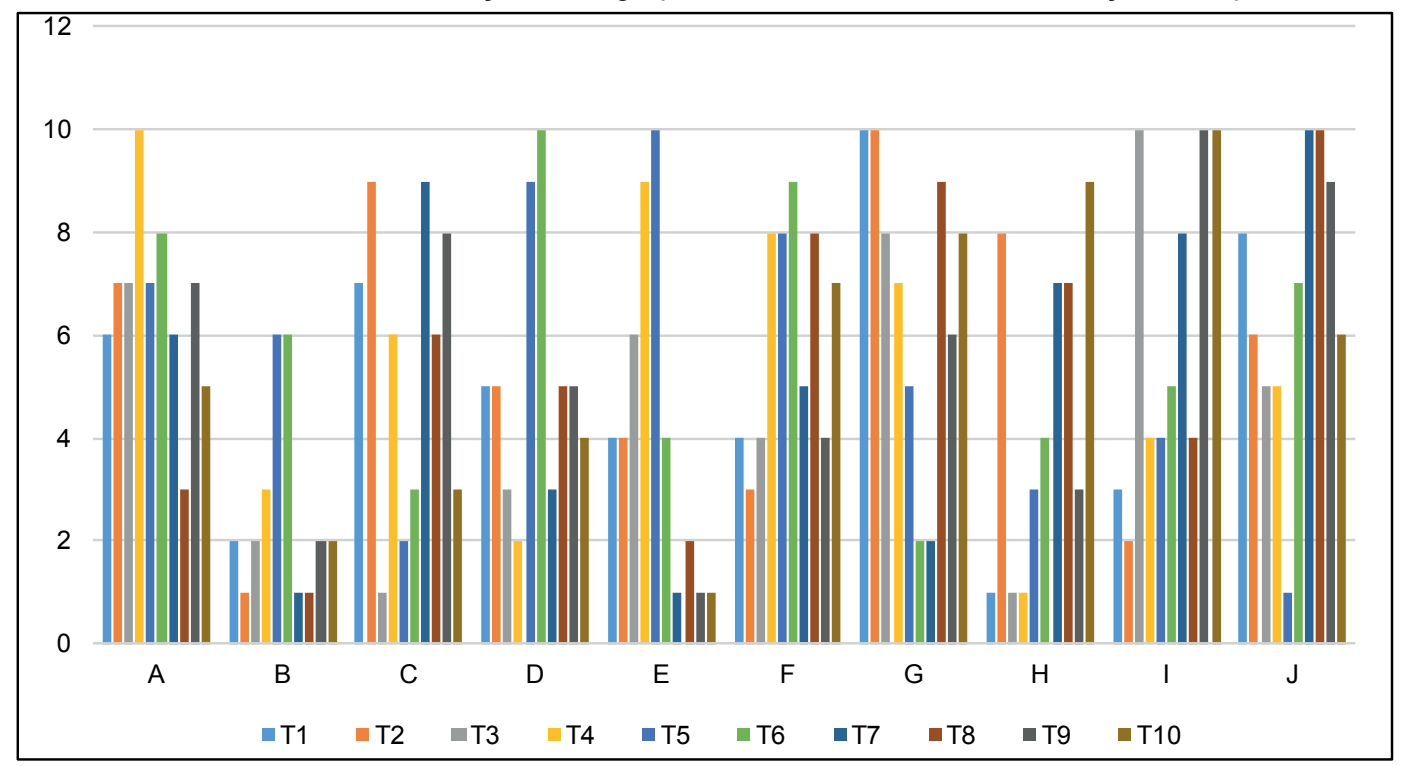

Fonte: elaboração do autor. 
Ao analisar o Gráfico 1, pode-se perceber que as colocações dos grupos de trabalho variam exacerbadamente, mas que todos concordam que as asserções criticidade, aprender a aprender e conhecimentos químicos são os pontos mais relevantes e benéficos na formação sociocultural do sujeito a partir do aprender pela pesquisa em sala de aula. Assim, para facilitar a compreensão dos dados, foi elaborado o Gráfico 2 a partir das colocações dos alunos no Gráfico 1, apresentado anteriormente, que demonstra, em média aritmética, as colocações dos sujeitos. A análise do Gráfico 2 auxilia na compreensão das asserções de destaque.

Gráfico 2 - Média aritmética das asserções pelas colocações dos grupos de trabalho

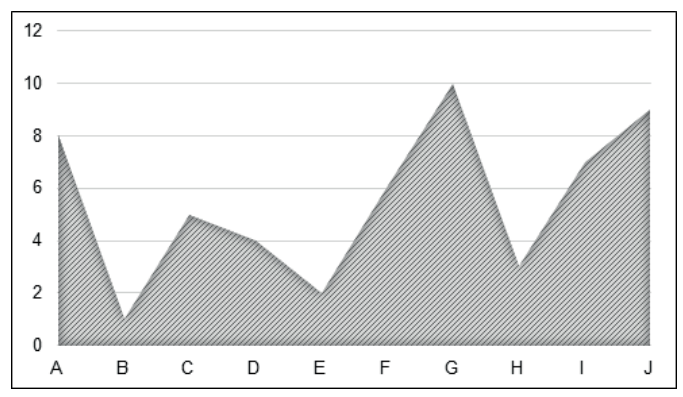

Fonte: autores, 2018.

Ao analisar o Gráfico 2, como supracitado, têm-se as asserções G, J e A com maior intensidade. Seguidamente, tem-se a ideia de que o aprender pela pesquisa torna-se relevante na formação sociocultural do sujeito por proporcionar saberes gerais sobre a química, aprender a pesquisar e interesse e curiosidade.
Assim, compreende-se que a metodologia Dicumba estimula a constituição da criticidade, da autonomia e, principalmente, da forma de aprender a aprender no sujeito, possibilitando ações significativas na formação dos próprios saberes científicos relevantes ao seu contexto.

Nessa perspectiva, "[...] toda experiência necessita de uma estruturação do real, isto é, que o registro de todo dado exterior supõe a existência de instrumentos de assimilação inerentes à atividade do sujeito" (PIAGET, 1988, p. 48). Assim, a formação de saberes químicos só é possível porque o aluno utiliza os saberes que preexistem em seu cognitivo, pois é a partir de sua veemência que a pesquisa tem início; cabe ao professor a ação de desafiar o estudante a pesquisar algo de sua vivência, a fim de que se permita utilizar e aplicar diferentes formas de aprender para se constituir.

A pesquisa para a formação crítica do cidadão dentro da sala de aula via metodologia Dicumba é vista pelos alunos como um mecanismo de qualificação na formação cidadã, em especial, por agregar saberes científicos ao conhecimento de mundo e ressignificá-los de forma coerente e concreta. $\mathrm{Na}$ escrita de um dos grupos, é possível, também, perceber, a partir da análise de conteúdos, que a pesquisa amplia conhecimentos e relaciona-os com a química. Por exemplo, T3 escreve que a pesquisa: 
esclareceu muitas dúvidas que tínhamos, além de nos deixar ainda com mais dúvidas. Fazendo este trabalho só aumento nosso conhecimento e vontade de nunca utilizar o cigarro, pois nele existe mais substâncias químicas do que imaginávamos e o quanto podemos prejudicar nossa saúde se utilizarmos ele.

Entre as apresentações sobre os impactos da pesquisa para a formação cidadã, por meio da análise de conteúdos, foi possível elencar algumas categorias que, grosso modo, demonstram especificamente o que os alunos pensam. Essas categorias estão no Gráfico 3.

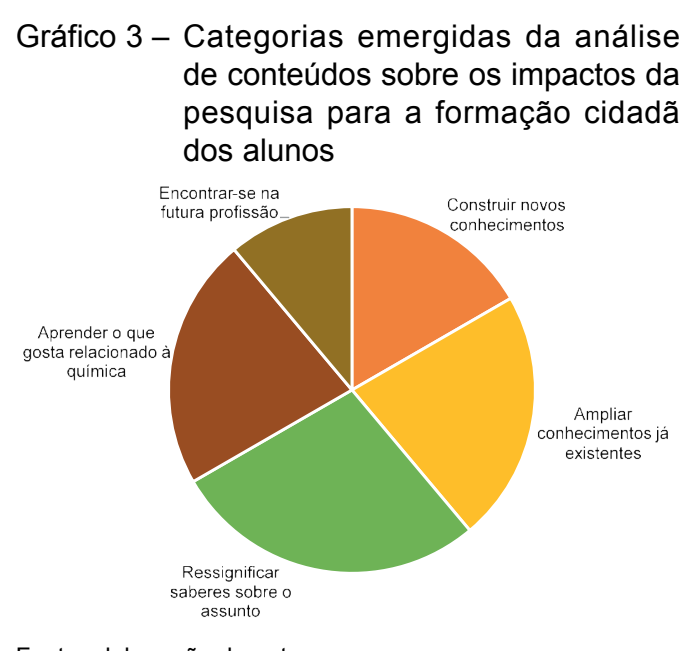

Fonte: elaboração do autores.

Com os dados supracitados, pode-se perceber que a metodologia Dicumba direciona os alunos para um ensino em que a construção e a reconstrução de informações em conhecimentos possibilitam a conscientização da prática discente como propulsora na própria formação, uma vez que proporcionam uma visão crítica sobre o próprio saber. Afinal, a ressignificação, a ampliação e a constituição de saberes ocorrem quando o aluno, por meio das provocações do professor, consegue modular o próprio conhecimento cognitivo, ampliando-o de forma significativa.

Assim, o ensino e a aprendizagem ocorrem de forma bilateral, uma vez que se fundamentam nas concepções de colaboratividade e cooperatividade. Os alunos aprendem química a partir daquilo que lhes é útil e agradável, com a estruturação cognitiva dos saberes preexistentes de forma científica. Piaget (2011) destaca que o desenvolvimento mental é uma constituição contínua, comparando-o à edificação de um prédio, em que, na

[...] medida que se acrescenta algo, ficará mais sólido, ou à montagem de um mecanismo delicado, cujas fases gradativas de ajustamento conduziram a uma flexibilidade e uma mobilidade das peças tanto maiores quanto mais estável se tornasse o equilíbrio (2011, p. 4).

Outra questão disponibilizada no questionário relacionava-se à aprendizagem do aluno via metodologia Dicumba. A partir das colocações dos sujeitos, foi possível elencar categorias na análise de conteúdo que demonstram, expressivamente, os principais saberes adquiridos pelos alunos. Essas categorias estão no Gráfico 4. 
Gráfico 4 - Saberes emergentes da análise de conteúdos sobre a aplicação da metodologia Dicumba

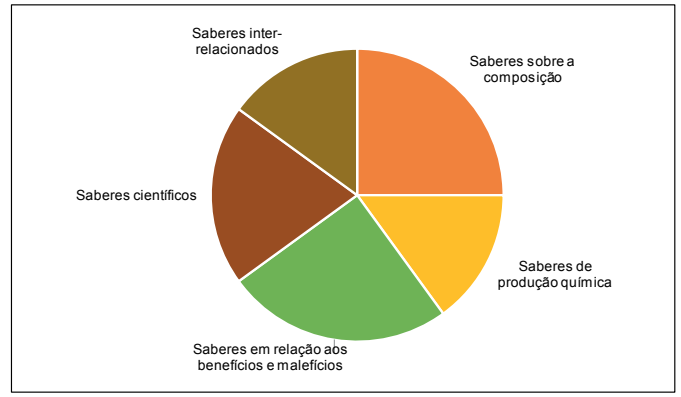

Fonte: elaboração do autores.

Para ilustrar a forma da emersão dessas categorias, traz-se a colocação de um integrante do grupo T8:

Eu aprendi algo que eu não poderia imaginar que poderia realmente acontecer, eu consegui ter uma noção real de como nosso cérebro é bem complexo e também consegui perceber a influência que os jogos trazem para nosso cotidiano. Conheci a dopamina que era algo que eu não fazia nem ideia de que existia, isso foi muito bom.

Colocações como a do grupo T8 demonstram que os alunos, por meio do aprender pela pesquisa, logram saberes, principalmente, referentes aos benefícios e malefícios do que foi pesquisado, assim como a composição da maioria dos compostos investigados, como perfume e maquiagem. Destaca-se, ainda, que muitos alunos comentaram sobre os processos químicos e físicos na produção de alguns compostos, tais como a cerveja e os smartphones; assim, foi possível, a partir da escrita, perceber a emoção e o entusiasmo pelo trabalho desenvolvido.
Esses saberes não seriam construídos nos alunos se o professor não tivesse utilizado a metodologia Dicumba, pois estaria centrado em um currículo fechado, que, geralmente, não apresenta conexões com as vivências dos alunos, buscando a constituição de ideias referentes a conhecimentos necessários para as avaliações, como exames e provas. Ainda, é necessário destacar que, por mais que o professor tivesse trabalhado com a pesquisa em sala de aula, ainda assim, não teria proporcionado ao estudante aprender sobre o supracitado, pois, sem a metodologia Dicumba, a pesquisa em sala de aula é arbitrária e referente a um conteúdo curricular; logo, de forma tradicional, parte do professor para o aluno, não o inverso.

Bordenave e Pereira (2002) expõem que o professor precisa planejar e orientar os alunos, buscando uma aprendizagem significativa por meio de estratégias de ensino que estimulem diversas capacidades do aprendizado. Os autores destacam que a observação, a liderança, a teorização e a síntese são fundamentais para a constituição do saber no aluno; todas essas ações podem ser vistas quando o aluno aprende pela metodologia Dicumba, pois ele observa o contexto para identificar um tema que lhe chama atenção e, liderando a própria pesquisa e as diferentes formas de pesquisar, elenca, de forma teórica, hipóteses e ações que possam solucionar 
diferentes problemas, sintetizados pela argumentação crítica.

O Gráfico 5 demonstra as categorias que emergiram a partir da análise de conteúdos na questão referente aos pontos positivos e negativos do aprender pela pesquisa em sala de aula. Destaca-se que os alunos, em sua totalidade, afirmaram não conseguir identificar pontos negativos do trabalho realizado, já que se apresentou de forma dinâmica e diferenciada.

Gráfico 5 - Categorias sobre os pontos positivos do aprender pela pesquisa em sala de aula

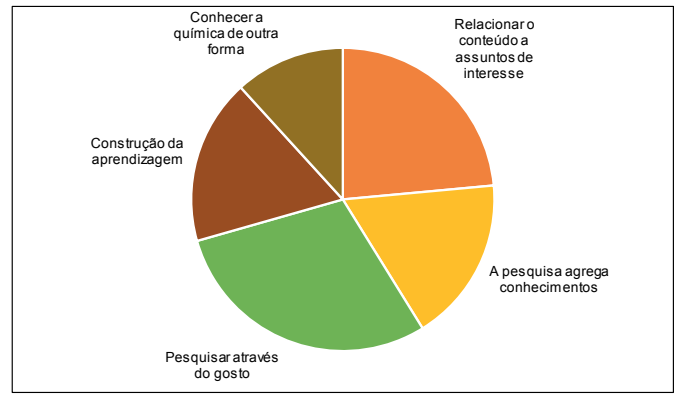

Fonte: elaboração do autores.

Percebe-se que são inúmeros os benefícios do uso do aprender pela pesquisa em sala de aula para a qualificação da aprendizagem discente, pois contribui para que o aluno desenvolva o aprender a partir de suas preferências, relacionando os saberes do contexto com o científico, a fim de agregar conhecimentos que levam à construção da aprendizagem em química. A realização dessa atividade desperta a motivação e o desejo de apren- der no aluno, pois é ele quem desenvolve toda a atividade.

Para intensificar as categorias emergentes, traz-se algumas colocações empíricas dos alunos sobre os pontos positivos de trabalhar com a metodologia Dicumba. Dentre elas, destacam-se:

T1: aprender química através de um assunto que gostamos e temos vontade de pesquisar e saber sobre é o ponto positivo.

T3: os positivos são muitos, como aprender mais sobre a matéria, como é formado o cigarro, a necessidade de entender melhor sobre as substâncias químicas; pontos negativos não tem nenhum, pois adoramos poder escolher um assunto para apresentar e poder tirar nossas conclusões fora da sala de aula.

T6: os pontos positivos são: que o assunto foi interessante e me fez querer aprender a parte da química dos produtos, me auxiliou a conhecer os componentes dos produtos químicos mais afundo, me deu mais fundamento sobre o assunto, este trabalho foi prazeroso de fazer e não um trabalho acumulado que tive que fazer por obrigação.

T7: aprendi sobre a fermentação que é um processo químico que eu acredito que muitas pessoas não sabem que existe, a grande maioria só compra cervejas importadas, sem saber quanto tempo leva para serem fabricadas.

T10: realmente eu não consigo encontrar pontos negativos, pois assim foi muito melhor para entender sobre o assunto e a química, já que ele estava envolvido em algo que eu gosto. Foi muito boa a ideia, pois é uma forma diferente de ensinar algo de uma maneira interessante que eu não havia experimentado antes (Questionário, 2017). 
Diante das colocações dos alunos, é cogente pensar que o aprender pela pesquisa é capaz de despir os alunos daquelas concepções corriqueiras ("química é difícil", "química é chata", "eu não gosto de estudar química", "eu não entendo química”, etc.), nas diferentes escolas do Brasil, pois, por meio da metodologia Dicumba, além de relacionar o contexto com os principais conceitos e conteúdos da disciplina química, sendo capaz de aprender de forma autônoma e crítica, o aluno consegue vislumbrar-se como autor da própria formação acadêmica.

\section{Reflexão final}

Este texto buscou apresentar uma proposta de ensino fundamentada na concepção do aprender pela pesquisa, por meio de uma atividade desenvolvida com alunos do segundo ano do ensino médio da rede pública, colocando-os como autores na formação do próprio saber, a partir daquilo que lhes é útil e significativo, para construir e reconstruir novos saberes científicos.

Em suma, a adjacência entre aluno, professor e conhecimento foi capaz de fortalecer os laços afetivos em sala de aula, permitindo um avanço significativo da aprendizagem de forma bilateral. Assim, por meio das conexões entre os saberes da vivência e os saberes científicos da disciplina de química, apresentados nas respostas dos alunos ao questionário, é possível pensar na formação significativa do aluno a partir da própria ação, tendo o professor como orientador/facilitador do processo de ensinagem.

Nessa perspectiva, por meio das categorias emergidas na análise de conteúdos, é necessário destacar que a metodologia Dicumba é fiel quanto ao desenvolvimento de atividades pedagógicas em sala de aula que levam os alunos à aprendizagem, pois se trata de algo inovador, sendo uma ideia para aprimorar e ressignificar os saberes, intensificando a busca por resolução de problemas concebidos a partir do desejo e do gosto do aluno.

Destarte, consideram-se as discussões e as ações sobre a proposta do aprender pela pesquisa como passos significativamente importantes e relevantes para as formações discente e docente, na medida em que conduzem as atividades em sala de aula e as ações de aprendizagem para a tomada de decisões de forma reflexiva e a emersão da argumentação crítica, fundamentando-se nos pressupostos epistemológicos de valores e condutas de um sujeito social, político e cultural.

Por fim, sugere-se que o aprender pela pesquisa seja, urgentemente, utilizado nas práticas pedagógicas nas diferentes escolas, buscando a formação do sujeito e a estruturação curricular do ensino a partir do contexto e da vivência do aluno, para, então, buscar construir 
conhecimentos científicos que sejam, realmente, necessários e significativos para os alunos. Ademais, o aprender pela pesquisa intensifica a necessidade de $o$ professor buscar uma formação continuada e qualificada nos saberes do conteúdo, de forma intradisciplinar, e nos saberes da didática, de forma universal.

\section{The Dicumba methodology as a storm of possibilities for the development of chemistry teaching}

\section{Abstract}

In this article presents the results of an investigative activity through Learning through Research in the light of the teaching methodology called Dicumba, providing the student with the connection of his experience with the knowledge of the content of chemical science and in the teacher the perception of the need for continuous training to perfect his intradisciplinary knowledge. The research that fits in qualitative-quantitative bias was developed during three months with the class of the Second Year of High School, being the data collection through participant observation and the application of a structured questionnaire; the data collected were interpreted in the light of Bardin's Content Analysis and presented through tables and graphs. At the end of the course, we can say that the Dicumba methodology is faithful to the development of pedagogical activities that lead the students to learning, since they place it something innovative, being an action to improve and re-signify knowledge in a universal-bilateral. Finally, it is suggested that learning through research is urgently incorporated into pedagogical practices, seeking the formation of the subject and the cur- ricular structuring from the context and the student's experience to then build scientific knowledge from now on chemical science.

Keywords: Student-centered learning. Learning by research. Methodology Dicumba.

\section{Nota}

1 Esta metodologia de ensino é inédita, criada pelos autores deste trabalho, tendo como motivação e princípio de emersão as angústias, as incertezas e os sentimentos envolvidos na construção de projetos de pesquisa lato sensu (especialização) e stricto sensu (mestrado e doutorado), realizados à luz do ensino de química na educação básica. Para constituí-la, foram realizados leituras e fichamentos das obras de Rogers (1947), Freire (1987, 2007) e Vygotsky (1989), objetivando ressignificar formas e maneiras de fazer com que o aluno desperte em si a motivação, a curiosidade e o interesse pelos saberes específicos do componente curricular química, valorizando a interpretação do seu contexto por meio dos saberes científicos.

\section{Referências}

ANASTASIOU, Léa das Graças Camargos; CAVALLET, Valdo José; PIMENTA, Selam Garrido. Docência no ensino superior construindo caminhos. In: BARBOSA, Raquel Lazzari Leite (Org.). Formação de educadores: desafios e perspectivas. São Paulo: Editora Unesp, 2003. p. 267-278.

BARDIN, Laurence. Análise de conteúdo. Lisboa: Edições 70, 2009.

70, 2011.

Análise de conteúdo. São Paulo: Edições

BASSO, Marcos Vinícius; NEVADO, Rosane; FAGUNDES, Léa. Projeto ECSIC - escola, conectividade e sociedade da informação e do conhecimento. 2003. Disponível em <http:// www.cinted.ufrgs.br/ciclo3/af/32-projetoecsic. pdf>. Acesso em: 23 jan. 2015. 
BEDIN, Everton. A emersão da interdisciplinaridade no ensino médio politécnico: relações que se estabelecem de forma colaborativa na qualificação dos processos de ensino e aprendizagem à luz das tecnologias de informação e comunicação. Tese (Doutorado em Educação em Ciências: Química da Vida e Saúde) - Instituto de Ciências Básicas da Saúde, Universidade Federal do Rio Grande do Sul, Porto Alegre, 2015.

BORDENAVE, Juan Díaz; PEREIRA, Adair Martins. Estratégias de ensino-aprendizagem. Petrópolis, RJ: Vozes, 2002.

BORUCHOVITCH, Evely; BZUNECK, José Aloyseo (Org.). A motivação do aluno: contribuições da psicologia contemporânea. 3. ed. Petrópolis: Vozes, 2004.

DEMO, Pedro. Educar pela pesquisa. 10. ed. Campinas: Autores Associados Ltda., 2015.

FREIRE, Paulo. Educação como prática da liberdade. 30. ed. São Paulo: Paz e Terra, 2007.

. Pedagogia do oprimido. 17. ed. Rio de Janeiro: Paz e Terra, 1987.

GALIAZZI, Maria do Carmo. Educar pela pesquisa: ambiente de formação de professores de Ciências. Ijuí: Unijuí, 2014.

GALIAZZI, M. C.; MORAES, R.; RAMOS, M. G. Educar pela pesquisa: as resistências sinalizando o processo de profissionalização de professores. Educar, Curitiba, n. 21, p. 227-241, 2003. Disponível em: <http://www.scielo.br/pdf/ er/n21/n21a15.pdf $>$. Acesso em: 20 jan. 2018.

GASKELL, George. Entrevistas individuais e grupais. In: BAUER, Willians Martins; GASKELL, George (Org.). Pesquisa qualitativa com texto, imagem e som: um manual prático. Petrópolis: Vozes, 2002. p. 64-89.

GIL, Antônio Carlos. Métodos e técnicas de pesquisa social. 5. ed. São Paulo: Atlas, 1999.

GLAZIER, Jack; POWELL, Ronald. Qualitative research in information management. Englewood: Libraries Unlimited, 2011.
LIBÂNEO, José Carlos. Organização e gestão da escola: teoria e prática. 6. ed. São Paulo: Heccus, 2013.

MENDES, Ana Magólia. Escuta e ressignificação do sofrimento: ouso de entrevista e análise categorial nas pesquisas em clínica do trabalho. In: CONGRESSO DE PSICOLOGIA ORGANIZACIONAL E DO TRABALHO, 2, 2006, Brasília. Anais... Brasília: Sociedade Brasileira de Psicologia Organizacional e do Trabalho, 2006. p. 9-22.

MORAES, R.; GALIAZZI, M. C.; RAMOS, M. G. Pesquisa em sala de aula: fundamentos e pressupostos. In: MORAES, R.; LIMA, V. M. R. (Org.). Pesquisa em sala de aula: tendência para a educação em novos tempos. 2. ed. Porto Alegre: EDIPUCRS, 2004. p. 09-24.

MÜLLER, Cândida Maria. Estágio e pesquisa: caminhos para a formação inicial do professor pesquisador. Revista de Ciências Gerenciais, Londrina, v. 11, n. 13, p. 101-109, 2007. Disponível em: <http://sare.unianhanguera.edu.br/ index.php/rcger/article/viewArticle/81>. Acesso em: 15 jan. 2018.

PATTON, Michael Quinn. Qualitative evaluation methods. Beverly Hills: Sage, 1980.

PIAGET, Jean. Psicologia e pedagogia. Rio de Janeiro: Forense Universitária, 1988.

Seis estudos de psicologia. 25. ed. Rio de Janeiro: Forense Universitária, 2011.

ROGERS, C. R. Some observations on the organization of personality. Toronto: York University, 1947.

VYGOTSKY. L. S. A formação social da mente. São Paulo: Martins Fontes, 1989. 